\title{
Desagrarização e agrarização da agricultura familiar em Salvador das Missões - Rio Grande do Sul
}

\author{
Deagrarianization and agrarianization of family farming in Salvador \\ das Missões - Rio Grande do Sul \\ Vanderlei Franck Thies ${ }^{1}$ (1), Marcelo Antonio Conterato² \\ 'Centro de Ciências Agrárias, Universidade Estadual do Oeste do Paraná (UNIOESTE), Marechal Cândido Rondon (PR), Brasil. \\ E-mail: vftc3@yahoo.com.br \\ 2Programa de Pós-Graduação em Desenvolvimento Rural (PGDR), Universidade Federal do Rio Grande do Sul (UFRGS), Porto \\ Alegre (RS), Brasil. E-mail: marcelo.conterato@ufrgs.br
}

Como citar: Thies, V. F., \& Conterato, M. A. (2023). Desagrarização e agrarização da agricultura familiar em Salvador das
Missões - Rio Grande do Sul. Revista de Economia e Sociologia Rural, 61(1), e245689. https://doi.org/10.1590/18069479.2021 .245689

Resumo: O presente artigo discute o processo de diferenciação social dos agricultores familiares utilizando o conceito de desagrarização. O objetivo é identificar a ocorrência de processos de desagrarização ou agrarização e analisar as implicações desses processos na diferenciação de agricultores familiares em Salvador das Missões (RS), Brasil. Para tal, propõe o Índice de Agrarização Familiar (IAF) como indicador síntese desses processos. A pesquisa teve caráter histórico e comparativo, com dados primários obtidos junto ao mesmo grupo de famílias, nos anos de 2003 e 2018. A amostra foi do tipo sistemática por comunidade e os dados foram obtidos com auxílio de questionário semiestruturado. Os resultados revelam que o processo de desagrarização envolve maior número de famílias e é mais intenso que o processo de agrarização, demarcando expressiva diferenciação das famílias ao longo do tempo. O IAF mostrou-se efetivo como indicador desses processos e introduz na literatura brasileira, de forma mais sistemática, a perspectiva da desagrarização/agrarização na análise das trajetórias das famílias agricultoras.

Palavras-chave: desagrarização, agrarização, agricultura familiar, diferenciação social no meio rural, pluriatividade.

\begin{abstract}
This article discusses the processes of social differentiation of family farmers using the concept of deagrarianization. It aims to identify the occurrence of deagrarianization and agrarianization processes and to analyze the implications of these processes in the family farming differentiation in Salvador das Missões (RS), Brasil. To this end, it proposes the Family Agrarianization Index (IAF) as an summary indicator for these processes. The research was historical and comparative, with primary data obtained from the same group of families, in the years 2003 and 2018. The sample was of the systematic type by community and the data were obtained with a semi-structured questionnaire. The results reveal that the deagrarianization process involves a larger number of families and is more intense than the agrarianization process, demarcating a significant differentiation of families over time. The IAF proved to be effective as an indicator of these processes and introduces into Brazilian literature, in a more systematic way, the perspective of agrarianization / deagrarianization in the analysis of the trajectories of farming families.
\end{abstract}

Keywords: deagrarianization, agrarianization, family farming, social differentiation in rural areas, pluriactivity.

\section{INTRODUÇÃO}

O conceito de desagrarização tem sido empregado esporadicamente na literatura brasileira que trata dos estudos agrários, aparecendo de forma periférica nos trabalhos (Anjos \& Caldas, 2005; 2007; Pontili et al., 2015; Favareto \& Berdegue, 2018). Já, na literatura internacional, o mesmo possui expressão um pouco mais alargada (Escalante et al., 2007; Grammont, 2009; Quintanal \& Fuente, 2013; Garcés et al., 2017; Bryceson, 2018, 2019), sendo especialmente 
utilizada desde as formulações pioneiras de Bryceson (1996). A força interpretativa desse conceito resulta da articulação analítica da noção de fluxos migratórios com as alterações econômicas no âmbito regional, local ou mesmo familiar. O conceito de desagrarização alude à redução da importância da agricultura na composição da renda e na absorção do trabalho, enquanto o conceito de agrarização expressa o processo inverso.

A agrarização e a desagrarização podem ser enfocadas em dois níveis. Um, de caráter macro e mesoanalítico, que envolve as variáveis gerais da economia de determinado recorte geográfico, por exemplo, de um país, ou de uma região especifica. No outro nível, no âmbito microanalítico, os processos de agrarização e desagrarização podem ser considerados no escopo das famílias agricultoras. O primeiro enfoque predomina amplamente na literatura, mas é no segundo viés que o presente artigo está focado.

A relevância do artigo, em termos empíricos, decorre das mudanças globais observadas nos espaços rurais, que envolvem aspectos: demográficos - expressiva presença de contingente populacional em muitos espaços rurais; econômicos - tendência declinante das ocupações e empregos agrícolas e a diversificação das fontes de renda das famílias rurais; e sociais - redução das diferenças culturais entre famílias urbanas e rurais e aumento da conectividade física e virtual das regiões rurais (Favareto \& Berdegue, 2018). Com graus variados nas diferentes regiões do globo, os referidos autores apontam que essas mudanças remetem a processos de desagrarização dos territórios rurais, sendo necessário, portanto, investigar esse fenômeno.

No cenário global tem se destacado que a agricultura parece estar "escapando", de forma intensa, das mãos dos agricultores e, pela primeira vez na história humana, como argumentam Niederle e Wesz Júnior (2018), os alimentos também são tratados como ativos financeiros altamente valorizados, compondo o portfólio dos negócios de fundos de pensão, bancos e investidores, sendo essa uma das dimensões da tendência resultante do domínio imperial sobre a agricultura e alimentação (Ploeg, 2008). Por outro lado, na contramão desse processo de industrialização, financeirização e globalização da agricultura destaca-se a emergência da valorização do local, sua cultura, suas práticas e o saber-fazer dos diversos agricultores, associados às questões de conservação ambiental (Bowen, 2011; Niederle, 2013; Diniz \& Cerdan, 2017).

No cenário nacional, sem desconhecer o esvaziamento dos campos, o processo de masculinização e de envelhecimento, as dificuldades de sucessão rural e a concentração da produção (Buainain et al., 2013; Maia, 2014; Anjos et al., 2014; Spanevello et al., 2017; Boscardin \& Spanevello, 2019), o fato incontestável é que ainda é expressiva a presença da agricultura familiar em amplos espaços do território nacional. Os dados do último Censo Agropecuário apontam que a agricultura familiar representa $76,82 \%$ dos estabelecimentos agrícolas no Brasil e $80,50 \%$ no Rio Grande do Sul (Instituto Brasileiro de Geografia e Estatística, 2017). Ou seja, os agricultores familiares são parte da realidade e compreender suas trajetórias específicas é uma das tarefas fundamentais na análise das dinâmicas do desenvolvimento rural contemporâneo.

Cabe destacar que, no caso brasileiro, a agricultura familiar ganhou maior evidência desde 0 final dos anos 1990, passando a ser reconhecida como importante ator social (Picolotto, 2011, Niederle et al., 2015), para o qual diversas políticas públicas específicas foram destinadas na primeira década e meia dos anos 2000 (Grisa \& Schneider, 2015; Belik, 2015), em contexto de forte expansão das commodities e da lógica imperial de agricultura (Ploeg, 2008; Silveira, 2017). Nesse cenário, o futuro dessa categoria social tem sido objeto de controvérsias entre os estudiosos do desenvolvimento rural.

Em termos teóricos, pretende-se contribuir com o aperfeiçoamento de abordagens e metodologias para o estudo das trajetórias históricas e a explicação das transformações longitudinais entre agricultores familiares (Ploeg, 2017), bem como incorporar novas lentes 
interpretativas para o trabalho de análise das mudanças nos espaços rurais (Favareto \& Berdegue, 2018). Além disso, os referenciais analíticos são instâncias abstratas que nunca estão absolutamente concluídos, pois são formulados em determinadas circunstancias históricas, sempre cambiantes (Schneider, 2009), o que implica a necessidade de permanente atualização das categorias de análise.

Nesse sentido, o argumento sustentado é que o conceito de desagrarização possui capacidade heurística para contribuir nos estudos sobre as dinâmicas rurais contemporâneas, o que justifica sua introdução na literatura brasileira. Assim, com base nas formulações pioneiras sobre desagrarização de Bryceson (1996), pretende-se contribuir no avanço dessa perspectiva analítica propondo e aplicando um indicador síntese para esse processo, considerando-se o âmbito específico da agricultura familiar de Salvador das Missões, Rio Grande do Sul (RS).

Todavia, avançar-se-á teoricamente nas formulações da referida autora ao incorporar-se no escopo analítico deste artigo um instrumento capaz de medir não somente a desagrarização das famílias, mas também o inverso desse processo, que é a ampliação da agrarização familiar ao longo do tempo. Assim, diferente da literatura corrente sobre desagrarização, a hipótese teórica que orienta o presente estudo é que a desagrarização não é o único sentido que a trajetória histórica dos agricultores familiares pode seguir, aceitando-se a possibilidade do seu contrário, qual seja, que essas famílias também podem seguir trajetórias agrarizantes ao longo do tempo.

Com essa ótica, o objetivo do artigo é identificar a ocorrência de processos de agrarização e desagrarização de agricultores familiares no município de Salvador das Missões (RS). Através da análise histórica e comparativa do mesmo grupo de famílias, em um intervalo de 15 anos, pretende-se, também, propor e testar um indicador desses processos, que permita reconhecer as distintas trajetórias históricas e a diferenciação das famílias agricultoras ao longo do tempo.

Após esta introdução, apresenta-se a delimitação conceitual da agrarização e da desagrarização. Para tal, buscou-se na literatura nacional e, sobretudo, na literatura internacional, os elementos para sua elaboração. Depois disso, explicitam-se os procedimentos metodológicos utilizados na pesquisa de campo e na produção dos dados e, na sequência, são apresentados e discutidos os resultados do estudo. Por fim, apresenta-se as considerações finais.

\section{REFERENCIAL TEÓRICO: DESAGRARIZAÇÃO E AGRARIZAÇÃO}

A desagrarização abarca amplo processo social, com múltiplas conexões e determinações. Tem sido utilizada na literatura internacional desde distintas perspectivas disciplinares, todavia, nas análises que acionam esse conceito é recorrente extrapolar os limites estritamente disciplinares, pois trata-se de um fenômeno multidimensional.

As análises dos processos de desagrarização contemplam abordagens econômicas e sociológicas, englobando questões relacionadas ao mercado de trabalho, emprego e renda, relações de trabalho (Gutiérrez \& Martín, 2006; Lui, 2013; Garcés et al., 2017), além da dimensão cultural e práticas sociais nos espaços rurais (Hernández \& Sánchez, 2010; Quintanal \& Fuente, 2013). Em todos esses trabalhos está presente a perspectiva histórica, destacando-se análises longitudinais das transformações, além da constante presença do componente demográfico (Gutiérrez, 2007; Anjos et al., 2014).

Completando o mosaico de usos da desagrarização, aparecem análises de estratégias de desenvolvimento rural (Banchirigah \& Hilson, 2010) e a discussão de temas transversais, como gênero e geração (Vázquez \& Mazariegos, 1991; Bryceson, 2019; Alatrista, 2019). O escopo territorial dos trabalhos é bastante variável, envolvendo microanálises - estudo de 
comunidades locais, ou a consideração das dinâmicas familiares (Manona, 1999; Rigg \& Nattapoolwat, 2001; Rehder et al., 2011), até análises mais amplas, que abarcam um país ou continente (Escalante et al., 2007; Grammont, 2009; Bryceson, 2018).

Também cabe registrar o uso da desagrarização em sentido adjetivo, mais genérico, sem uma definição conceitual muito precisa (Collantes, 2002; Gutiérrez, 2007). Ou seja, trata-se de um conceito apropriado por diferentes áreas da ciência e que, frente a tão diversos usos, apresenta ênfases que também têm distinções, mas todas apontam para a redução da centralidade da agricultura nos espaços rurais e entre as populações camponesas.

A desagrarização pode ser compreendida como o declínio da atividade agrícola na economia nacional, na geração de renda e na ocupação da população rural, com a tendência de redução do grau de importância da agricultura como setor econômico, além de envolver a migração e o envelhecimento da população do campo (Escalante et al., 2007; Anjos \& Caldas, 2005). Conforme Lui (2013), trata-se do fenômeno de afastamento das populações rurais das atividades agrícolas, especialmente na alocação de trabalho e como fonte geradora de renda das famílias.

Para Anjos \& Caldas (2007), o fenômeno da desagrarização resulta da queda na importância específica da agricultura na composição da riqueza nacional e de sua capacidade declinante em ocupar satisfatoriamente a população residente nos espaços rurais, estando associada à ampliação da capacidade produtiva da agricultura e sua crescente integração aos mercados nacionais e internacionais.

Conforme Fra (2016), o processo de deterioração sofrido por áreas rurais está intimamente associado ao fenômeno da desagrarização, sendo decorrente da baixa elasticidade de renda dos alimentos e da integração agroindustrial, que provoca o declínio relativo do setor agrícola. $\mathrm{Na}$ perspectiva da referida autora, o conceito refere-se à redução absoluta e relativa do emprego agrícola, o que, no longo prazo, é consequência inevitável do desenvolvimento econômico.

A desagrarização pode decorrer da ação de diferentes fatores, que conduzem à diversificação das rendas das famílias rurais, como: maior valorização da remuneração individualizada tendo como referência os rendimentos do trabalho, como é o caso de salários; desvalorização do papel social do agricultor; e insatisfação dos mais jovens com o trabalho rural, que desestimula seu engajamento em atividades agrícolas (Lui, 2013). Tais circunstâncias levam à redução da importância destas atividades na composição dos rendimentos totais e ao processo de esvaziamento da dimensão agrícola nos espaços rurais, sem necessariamente levar ao abandono do campo. Essas mudanças, substantivas nas dinâmicas familiares não são captadas pela noção de êxodo rural, mas podem ser identificadas desde o conceito de desagrarização.

Cabe destacar que a pluriatividade e a desagrarização permitem abordar o fenômeno da interação entre as dinâmicas agrícolas e não-agrícolas nos espaços rurais, todavia com enfoques distintos e complementares. A pluriatividade é considerada como uma das estratégias que pode ser adotada por determinada família agricultora na busca de sua reprodução social, enquanto a desagrarização é considerada como resultado de distintas estratégias, entre elas a pluriatividade. Esta última está circunscrita às escolhas que as famílias realizam, em determinadas circunstâncias, em relação à alocação do trabalho familiar e à composição de rendas, através da combinação de atividades agrícolas e não agrícolas, enquanto a desagrarização, além daquelas, também inclui a consideração das estratégias que, majoritariamente, distanciam a vida das famílias agricultoras dos espaços rurais e, especialmente, das atividades agrícolas enquanto provedoras de trabalho e rendimentos monetários.

Na perspectiva de análise das famílias rurais, que compõem o escopo do presente estudo, baseado em Bryceson (1996), a desagrarização é compreendida como um processo de reorientação das atividades familiares, na qual a produção agrícola perde espaço e ocorre a redução da sua 
importância na alocação do trabalho familiar. Associado a este fenômeno, as famílias promovem a realocação domiciliar, com distanciamento dos espaços rurais. Portanto, a noção de desagrarização articula as dimensões renda, trabalho e localização domiciliar dos agricultores familiares.

Todavia, como deve ter notado o atento leitor, até o presente momento, conceituou-se apenas a desagrarização, não tendo-se mencionando o processo de agrarização. No conjunto dos trabalhos consultados, especialmente na literatura internacional, tal foco mostra-se bastante frequente, com desconsideração da possibilidade de ocorrência de processos de agrarização, aceitando-se tacitamente a desagrarização como a única e inexorável trajetória possível. Com certo ineditismo na literatura, o presente artigo diferencia-se dos estudos que utilizam o conceito de desagrarização nessa perspectiva unilateral, pois considerar-se-á agrarização e desagrarização, em termos teóricos, de forma isonômica. Não proceder dessa forma implica em elevado risco para a análise, por negligenciar relevantes dimensões dos processos de transformação nos espaços agrários.

A perspectiva da agrarização foi utilizada por Lui (2013), que criou três índices para mensurar o maior ou menor nível de agrarização das famílias. O primeiro deles é o Índice de Agrarização da Atividade Familiar, calculado pela razão entre o número de indivíduos que se autodeclaram agricultores e o número total de indivíduos da família. Esse índice mede a dimensão subjetiva da auto identificação dos sujeitos, mas se constitui como um indicador limitado em relação as atividades que eles desenvolvem, pois anula a possibilidade de identificar aqueles que se auto definem como agricultores, mas que também realizam atividades não agrícolas, bem como daqueles que não se auto definem como agricultores, mas que realizam atividades agrícolas. Ou seja, o fenômeno da pluriatividade não é captado com o uso desse índice. O segundo é o Índice de Comercialização da Produção, que é calculado, tão somente, pela razão entre o número de variedades comercializadas e o número total de espécies produzidas, constituindose como indicador parcial da maior ou menor mercantilização das atividades agrícolas, pois toma somente uma das dimensões do processo de produção e venda, que é o número de espécies produzidas. Ao não considerar volumes produzidos, tempo de trabalho necessário e preços de venda, esse índice possui limitada capacidade de contribuir na compreensão da participação da produção agrícola na formação da renda e também na absorção do trabalho familiar. Por fim, o Índice de Agrarização da Renda, que busca medir a participação da renda agrícola na renda total, apresenta como limite o fato de calcular a renda agrícola considerando apenas aquela originada em atividades e produtos do próprio lote familiar, sem considerar rendas oriundas de trabalho agrícola fora do próprio lote. O trabalho de Lui (2013) tem o mérito de propor parâmetros para mensurar o processo de agrarização no âmbito das famílias agricultoras, tendo contribuído para o aprimoramento dos parâmetros utilizados no presente estudo, que busca superar as limitações à métrica proposta pelo referido autor.

A agrarização é entendida como o processo em que aumenta a importância das atividades agrícolas na produção de riquezas, na geração de renda e na alocação do trabalho familiar, de forma combinada com a utilização dos espaços rurais como espaços predominantes de localização dos domicílios das famílias. Portanto, a agrarização representa a face inversa do processo de desagrarização. Em termos mais específicos, os processos de agrarização e desagrarização serão operacionalizados neste artigo enfocando as famílias agricultoras segundo três dimensões: (1) a participação relativa da alocação do trabalho familiar em atividades agrícolas e não-agrícolas, em âmbito interno e externo à própria unidade de produção; (2) a importância relativa da renda com origem em atividades agrícolas na composição da renda total das famílias; (3) a variação na localização dos domicílios entre espaços rurais e espaços urbanizados.

Por fim, é importante sublinhar que o foco do presente estudo recai sobre as famílias agricultoras, discutindo como se transformam ao longo do tempo e desenvolvem respostas 
nos diferentes contextos em que estão inseridas, considerando, portanto, sua capacidade de agência e sua atuação como atores sociais (Long, 2007; Long \& Ploeg, 2011). Dessa maneira, trata-se de duplo propósito: primeiro, reconhecer e ratificar a importância das dinâmicas e variáveis meso e macro nos processos de desenvolvimento'; segundo, enfatizar que o foco dos dados e análise apresentada no presente trabalho está centrada no nível microanalítico, qual seja, o escopo das famílias agricultoras.

\section{PROCEDIMENTOS METODOLÓGICOS}

\subsection{Delimitação da área pesquisada}

O município de Salvador das Missões localiza-se na microrregião de Cerro Largo, no noroeste do Rio Grande do Sul, como se observa na Figura 1. Encontra-se a cerca de 409 km da capital Porto Alegre. A população do município variou de 2.665 para 2.669 pessoas entre 2000 e 2010, todavia o contingente rural passou de $68 \%$ para $59 \%$ da população municipal (Instituto Brasileiro de Geografia e Estatística, 2000, 2010). A dinâmica demográfica municipal segue a tendência nacional, que aponta a continuidade do processo de êxodo rural, com certo arrefecimento no período mais recente (Camarano \& Abramovay, 1999; Anjos \& Caldas, 2005; Anjos et al., 2014), sendo bastante similar às dinâmicas estadual e, especialmente, da região onde o município está inserido, tornando-o representativo da dinâmica populacional regional.

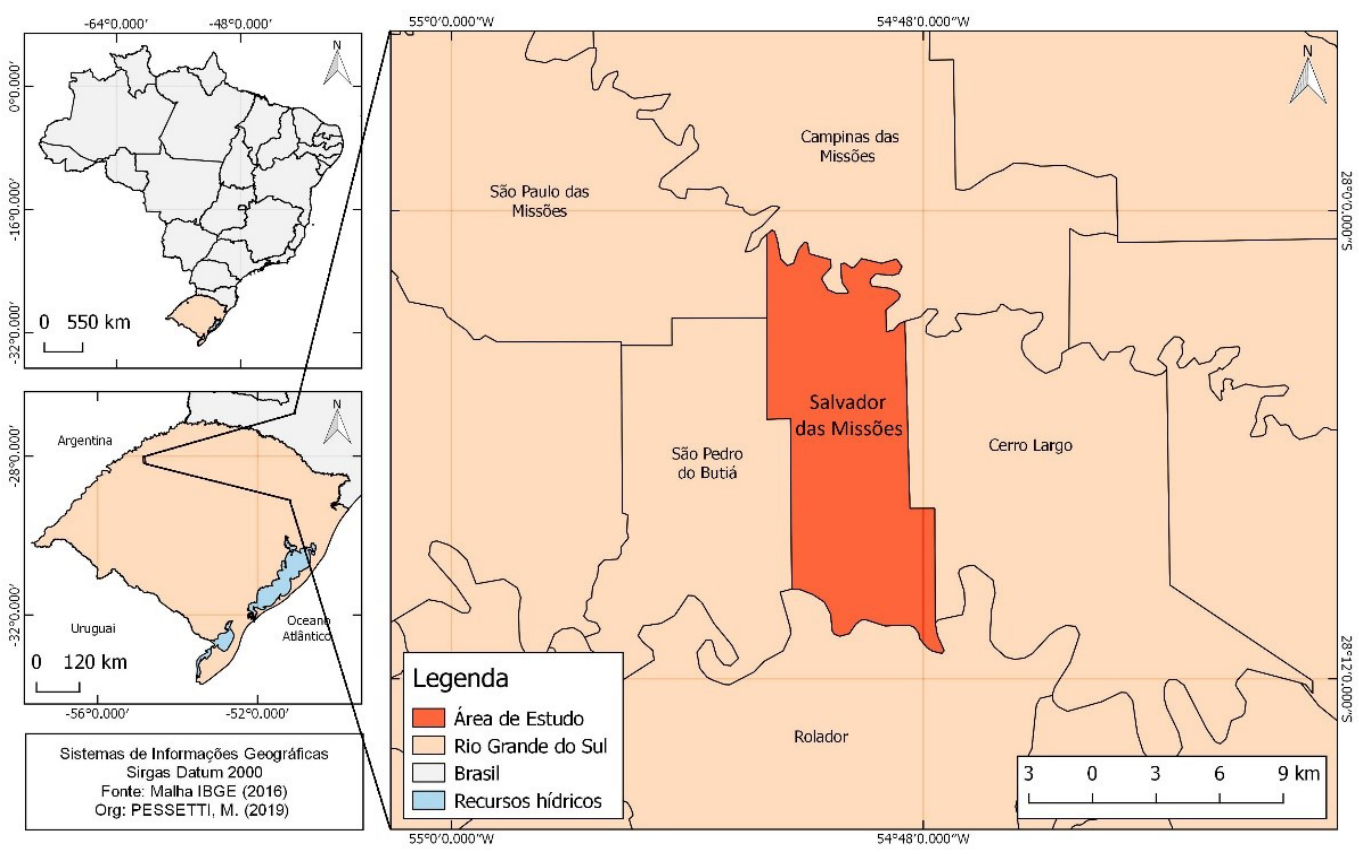

Figura 1: Localização do município de Salvador das Missões - RS. Fonte: Elaboração dos autores.

\footnotetext{
1 Para destacar apenas alguns trabalhos nesta dimensão: sobre crescimento dos preços internacionais dos produtos agrícolas e o aumento da produção agropecuária no Brasil, veja-se Silveira (2017); sobre as políticas internas de apoio aos agricultores, pode-se ver Belik (2015) e Black (2015), ou os livros organizados por Sabourin et al. (2015) e Grisa \& Schneider (2015); sobre os preços das terras, recomenda-se Bacha et al. (2016); sobre arrendamento de terras no Brasil, veja-se Guedes et al. (2018); sobre sistemas alimentares e as conexões campo e cidade, ver Preiss \& Schneider (2020).
} 
A agricultura familiar tem densa presença em Salvador das Missões, pois corresponde a 86,19\% dos estabelecimentos e ocupa 75,16\% das áreas rurais, respondendo por 75,29\% do valor produzido pela agricultura (Instituto Brasileiro de Geografia e Estatística, 2017). A produção para autoconsumo, combinada com a produção de leite e grãos, destacadamente soja e milho, é recorrente entre agricultores familiares da região noroeste do estado e, de forma mais ampla, no sul do Brasil (Grando, 2012; Souza \& Buainain, 2013), o mesmo sendo observado em Salvador das Missões. Assim, esse município apresenta características similares ao panorama regional, em termos da dinâmica populacional, da presença da agricultura familiar e de sistemas produtivos tipicamente desenvolvidos por essa categoria social, o que o torna interessante espaço de observação das transformações contemporâneas nos espaços rurais e para a verificação da existência dos processos de agrarização e desagrarização entre os agricultores familiares.

\section{2 o caráter da pesquisa e a geração dos dados}

O estudo está baseado no método histórico e comparativo, pois considera a continuidade e o entrelaçamento dos fenômenos do passado e do presente, analisando as semelhanças e diferenças de um mesmo grupo social ao longo do tempo (Marconi \& Lakatos, 2010). A unidade de análise utilizada é a família dos agricultores familiares (Schneider, 2003), portanto cada família constitui um caso. Os dados são de fonte primária e foram coletados com as mesmas famílias, num intervalo de tempo de 15 anos.

O principal instrumento de coleta de dados, nos dois anos da pesquisa, foi um questionário semiestruturado, composto por diferentes blocos de questões. Os blocos foram os seguintes, com algumas das dimensões específicas consideradas: a unidade doméstica - a família e seus componentes (idade, sexo, escolaridade, migração, etc.); as condições produtivas - estrutura fundiária, o capital e o trabalho disponível (forma de obtenção da terra, área total disponível, benfeitorias, máquinas, alocação do trabalho, etc.); os sistemas produtivos - o trabalho e o processo de produção animal e vegetal, destino da produção, etc.; o valor gerado - as rendas agrícolas e não agrícolas, valor agregado, valor bruto da produção, valor líquido, formação das rendas, etc.; aspectos sociais e políticos que afetam a agricultura familiar e o desenvolvimento local - participação política, meios de comunicação, expectativas sobre o futuro e os filhos, etc.; as políticas públicas e o papel do Estado - acesso à assistência técnica, financiamento, Previdência Social, políticas locais, mercados institucionais, etc.

A primeira coleta de dados, com uso do questionário, foi realizada em janeiro e fevereiro de 2003 (referente ao ano agrícola 2001-2002)². A construção do questionário foi amparada em instrumentos de coleta de dados de outros projetos de pesquisa e passou por dois testes de campo para aprimoramento. Ele pode ser acessado em Conterato (2004). A amostragem foi do tipo probabilística, englobando $10 \%$ dos agricultores familiares de cada comunidade, sendo escolhidas através de sorteio, o que resultou no total de 58 famílias pesquisadas. Optou-se por

\footnotetext{
2 Essa coleta de dados foi realizada no âmbito do projeto de pesquisa denominado Agricultura Familiar, Pluriatividade e Desenvolvimento Local no Rio Grande do Sul: a emergência de uma nova ruralidade (AFDLP). Esse projeto foi realizado no início dos anos 2000, com financiamento do Conselho Nacional de Desenvolvimento Científico e Tecnológico (CNPq), tendo por objetivo compreender a dinâmica da agricultura familiar e suas conexões com o desenvolvimento local, considerando especialmente o papel das atividades e rendas não-agrícolas na reprodução social das famílias rurais. A pesquisa foi realizada em conjunto por pesquisadores da Universidade Federal do Rio Grande do Sul (UFRGS) e da Universidade Federal de Pelotas (UFPel), abrangendo os municípios de Veranópolis, Três Palmeiras, Morro Redondo e Salvador das Missões, todos no Rio Grande do Sul. O acesso ao banco de dados deste último município possibilitou o desenvolvimento do presente trabalho, realizado em parceria entre a UFRGS e a Universidade Federal da Fronteira Sul (UFFS - Cerro Largo).
} 
essa amostragem sistemática por comunidade para garantir a representatividade de todos os espaços rurais do município.

A amostra foi constituída por famílias que praticassem alguma atividade econômica de exploração animal, vegetal ou de transformação primária, destinadas para a venda ou para o consumo da própria família. Além disso, considerou-se as famílias como sendo formadas por indivíduos com algum grau de parentesco, que compartilhassem o local de residência e vivessem em regime de economia familiar. Em termos operacionais, a amostra também foi limitada por famílias que desenvolviam as atividades em áreas de até seis módulos fiscais e em caso de contratação de trabalho externo, esse não deveria exceder o volume do trabalho familiar (Grupo de Estudos e Pesquisas em Agricultura Familiar e Desenvolvimento Rural, 2004).

A segunda coleta de dados foi realizada em janeiro de 2018, referente ao ano agrícola de 2016-2017. Todas as 58 famílias pesquisadas, em 2003, foram localizadas e entrevistadas, em janeiro e fevereiros de 2018. O questionário do primeiro ano da pesquisa foi reaplicado, contendo as questões originais e novas perguntas foram incorporadas no segundo ano da pesquisa. Os mesmos procedimentos foram adotados no levantamento dos dados de campo nos dois anos pesquisados, utilizando-se como referência as recomendações do "Manual do Pesquisador", que foi elaborado especificamente para orientar o trabalho de campo e uso do referido questionário (Grupo de Estudos e Pesquisas em Agricultura Familiar e Desenvolvimento Rural, 2004). O questionário do segundo ano da pesquisa pode ser acessado em Thies (2020).

Cabe destacar que todos os valores monetários de 2002 foram atualizados para 2017, utilizando-se o Índice Geral de Preços do Mercado (IGPM), que é calculado pela Fundação Getúlio Vargas (FGV) e está disponível no site do Banco Central do Brasil. Os dados coletados nos dois anos da pesquisa foram digitalizados e considerados através de análise histórica e comparativa, valendo-se da técnica de comparação de painéis e utilizando-se estatística descritiva.

Os dados coletados abarcaram informações referentes à configuração dos sistemas produtivos, à alocação do trabalho e à composição da renda das famílias, utilizando os procedimentos apontados por Lima et al. (1995), além de informações domiciliares, segundo os parâmetros que seguem.

- Superfície Agrícola Útil (SAU): é a parte da área total efetivamente utilizada pelos sistemas produtivos, sendo medida em hectares.

- Unidade de trabalho homem (UTH): equivale a 300 dias de trabalho de oito horas, sendo calculada considerando-se a idade e o tempo dedicado às atividades produtivas. Quanto à idade, considerou-se: 1,0 UTH (de 18 a 59 anos); 0,75 UTH (de 14 a 17 anos, ou mais de 60 anos); 0,5 UTH (de 7 a 13 anos); nos casos de pessoas que estudam um turno, contabilizouse somente $50 \%$ desse valor.

- Trabalho agrícola (TA): é obtido pela soma das UTHs familiares alocadas em trabalho agrícola, dentro ou fora do próprio estabelecimento familiar.

- Trabalho não-agrícola (TnA): é a soma das UTHs familiares que são alocadas em atividades não-agrícolas, dentro ou fora do estabelecimento familiar.

- Trabalho total (TT): é a capacidade total de trabalho da família, obtida pela soma do TA com o TnA.

- Renda agrícola (RA): é a parte do valor gerado no processo de produção que fica com o agricultor, englobando a renda gerada pela produção comercializada e também aquela destinada ao consumo familiar.

- Outras rendas do trabalho agrícola (ORT): obtida necessariamente fora da unidade de produção e procedente de atividades internas ao setor agropecuário. Envolve a venda de força de trabalho na agricultura, ou prestação de serviços agrícolas. 
- Renda não-agrícola (RnA): oriunda de atividades fora do setor agropecuário, podendo ser realizada dentro ou fora da unidade de produção familiar, tanto na posição de empregado, empregador ou trabalhador por conta própria.

- Renda de outras fontes (ROF): oriunda de doações de outros familiares, juros, aluguéis, venda de equipamentos, empréstimos ou do arrendamento de terra.

- Renda de aposentadoria e outras transferências sociais (RAPOS): resulta de transferências governamentais, especialmente de aposentadoria e pensão por morte, mas também de benefícios sociais e programas assistenciais, como o Programa Bolsa Família. Entre as famílias estudadas a aposentadoria responde, praticamente, por todos os recursos desta fonte, por isso é denominada de renda de aposentadoria.

- Renda total (RT): resulta da soma da renda agrícola, outras rendas do trabalho, renda não agrícola, renda de outras fontes e renda de aposentadoria.

\subsection{O Índice de Agrarização Familiar}

Partindo da base conceitual desenvolvida por Bryceson (1996), foi criado um índice para mensurar o nível de agrarização das famílias em cada um dos anos pesquisados. Esse índice foi denominado de IAF - Índice de Agrarização Familiar. O IAF é composto por dimensões que compõem a base do processo de desagrarização (Bryceson, 1996), todavia foram traduzidas para o escopo do presente trabalho, que toma a família dos agricultores como unidade de análise. Assim, três dimensões integram o IAF: a composição da renda, a distribuição do trabalho e a localização do domicílio. Elas foram operacionalizadas da seguinte forma:

- Índice de Agrarização da Renda (IAR): representa a participação dos rendimentos originados das atividades agrícolas (RA e ORT) na renda total da família. A fórmula de cálculo é (Fórmula 1):

$I A R=(R A+O R T) / R T$

- Índice de Agrarização do Trabalho (IAT): representa a participação do trabalho agrícola (TA) na capacidade total de trabalho (TT) da família. O IAT é calculado pela Fórmula 2:

$I A T=(T A / T T)$

- Índice de Agrarização Domiciliar (IAD): representa a maior ou menor urbanização do domicilio familiar, sendo atribuídos os seguintes valores: zero - domicílio em cidade; 0,5 - domicílio em vila rural; 1 - domicílio em espaço rural sem aglomerações domiciliares.

- Índice de Agrarização Familiar (IAF): indica a maior ou menor vinculação das famílias com as atividades agrícolas e os espaços rurais. É calculado através da seguinte Fórmula 3:

$I A F=(I A R+I A T+I A D) / 3$

O IAR indica a contribuição das rendas obtidas em atividades do setor agrícola (RA e ORT) em relação à renda total da família. Assim, quanto mais próximo de 1, mais agrarizada a renda familiar e o inverso ocorre quanto mais próximo de zero for esse índice, apontando, nesse caso, que as rendas familiares provêm de fora do setor agrícola. O IAT indica a proporção do trabalho total disponível da família que é alocada em atividades no setor agrícola, dentro ou fora da unidade de produção familiar. Quanto mais próximo de 1, mais agrarizado é o trabalho familiar e, quanto mais próximo de zero, menos agrarizado, ou seja, a alocação do trabalho 
familiar se concentra fora do setor agrícola. Já o IAD indica a maior ou menor urbanização do espaço de moradia da família.

Considerados de forma combinada, esses três índices (IAR, IAT e IAD) resultam no que se denomina de agrarização das famílias, expressa através do IAF. Sua variação ao longo do tempo aponta o maior ou menor afastamento das famílias em relação às atividades agrícolas, bem como o maior ou menor distanciamento de seus domicílios em relação aos espaços urbanizados. Quanto mais próximo de 1 for o valor do IAF, mais agrarizada a família, sendo que esse valor representa uma família que aufere todos os seus rendimentos de atividades agrícolas (dentro ou fora de sua unidade de produção), aloca todo o trabalho familiar em atividades agrícolas (dentro ou fora de sua unidade de produção) e reside em espaço rural não urbanizado. Do contrário, se o índice tiver valor zero, trata-se de família que obtém todos os rendimentos fora do setor agrícola, não aloca nada de trabalho familiar nesse setor e possui seu domicílio na cidade. Assim, se o valor do IAF de uma família aumenta, entre os dois anos pesquisados, tem-se um processo de agrarização familiar. Do contrário, se o valor do IAF diminui, tem-se o processo de desagrarização familiar.

\section{RESULTADOS E DISCUSSÃO}

\subsection{Agrarização e desagrarização da agricultura familiar em Salvador das Missões}

Nessa seção, apresenta-se os resultados da aplicação do índice proposto. O IAF é utilizado como recurso metodológico para identificar a existência, ou não, dos processos de agrarização e desagrarização entre as famílias pesquisadas. Na Tabela 1 estão apresentados os valores do índice que traduzem esses processos. Nela observa-se que, no conjunto dos casos pesquisados, ocorreu redução do IAF entre 2002 e 2017, que passou de 0,78 para 0,68. Ou seja, ocorreu expressiva desagrarização das famílias.

Tabela 1 - IAF desagregado das famílias de Salvador das Missões, 2002 e 2017.

\begin{tabular}{cccc} 
Índices & $\mathbf{2 0 0 2}$ & $\mathbf{2 0 1 7}$ & Variação 2002-2017 \\
IAR & 0,65 & 0,61 & $-6,33 \%$ \\
IAT & 0,87 & 0,78 & $-10,98 \%$ \\
IAD & 0,83 & 0,66 & $-20,83 \%$ \\
IAF & 0,78 & 0,68 & $-13,16 \%$ \\
\hline
\end{tabular}

Fonte: Pesquisa AFDLP (Grupo de Estudos e Pesquisas em Agricultura Familiar e Desenvolvimento Rural, 2004) e pesquisa de campo 2018.

Esse primeiro resultado da pesquisa acompanha a tendência geral de desagrarização apontada por estudos em outros países, a exemplo dos trabalhos de Bryceson (2018) na África, de Escalante et al. (2007) e Grammont (2009) no México, Gutiérrez (2007) na Espanha e Rehder et al. (2011) na Tailândia. No caso do Brasil, os trabalhos de Lui (2013) e Anjos et al. (2014) apontam em perspectiva semelhante. Cabe destacar que esses autores utilizam distintas métricas para mensurar o fenômeno da desagrarização mas, em acordo com os resultados deste artigo, todos apontam, em termos de totalidade, na mesma perspectiva: o crescente distanciamento das famílias agricultoras das dinâmicas estritamente agrícolas e o progressivo afastamento domiciliar dos espaços rurais.

Ao se considerar o IAF desagregado, conforme se observa na Tabela 1, percebe-se a diminuição do índice de agrarização das famílias em relação à renda, ao trabalho e ao domicílio. A taxa de 
variação dessas três dimensões evidencia que na variável domicílio ocorreu a maior redução relativa. Esse dado significa que a alteração do local de residência das famílias é a dimensão que, relativamente, mais contribuiu para a desagrarização das famílias estudadas, ainda que, é importante registrar, os limites que separam rural e urbano no espaço estudado são tênues. $A$ expressiva variação no IAD decorre do fato de que, entre as 58 famílias pesquisadas, 13 delas alteraram o local do domicílio, sendo que sete migraram de área rural para cidade e outras seis de área rural para vila rural, não sendo registrado nenhum movimento em sentido inverso.

A desagrarização do trabalho, captada através da diminuição do IAT, corrobora o argumento de Kageyama et al. (2013), que apontam a importância do trabalho externo aos estabelecimentos rurais no Brasil, em que cerca de um quinto das pessoas que os integram possuem remuneração fora do estabelecimento. De forma mais específica, Sakamoto et al. (2016) e Escher et al. (2014) apontam a tendência de redução das famílias com atividades exclusivamente agrícolas no meio rural, revelando a importância da pluriatividade, com crescimento das atividades e das rendas não-agrícolas entre as famílias agricultoras, o que também é captado, nos casos estudados, através da redução no IAT e no IAR.

Nesse sentido, o índice proposto mostra-se efetivo ao captar os fenômenos associados à crescente importância das atividades não-agrícolas entre as famílias agricultoras, como já apontado pela literatura (Silva, 2001; Schneider, 2003; Anjos \& Caldas, 2007). Ainda que também aponte para o processo de redução da importância da agricultura nos espaços rurais, o IAF, ao incorporar outras dimensões além do trabalho, possibilita perceber aspectos da realidade rural que não são captados desde as abordagens utilizadas nos referidos trabalhos, bem como em estudos mais recentes sobre a pluriatividade (Kageyama et al., 2013; Escher et al., 2014; Sakamoto et al., 2016), o que possibilita complementar e aprofundar a compreensão das dinâmicas rurais.

Desde a perspectiva conceitual da desagrarização e de sua operacionalização, através do IAF, uma nova faceta do desenvolvimento rural pode ser apreciada. Apesar da tendência geral de desagrarização do conjunto dos casos estudados, ao se considerar a trajetória individual das famílias, observa-se que a redução do nível de agrarização ocorre em cerca de dois terços dos casos (38 famílias). Ou seja, nem todas as famílias vivenciaram um processo de desagrarização, pois para um terço delas (18 famílias) ocorreu elevação do IAF.

Evidenciar e mensurar, através do IAF, o processo de desagrarização entre as famílias pesquisadas é um resultado bastante importante, pois a desagrarização, usualmente, na literatura nacional tem sido usada de forma bastante genérica e imprecisa. Outra contribuição importante, especialmente para a literatura internacional, é que o uso do IAF permite lançar luz sobre o processo de agrarização das famílias, viés fortemente negligenciado nos estudos rurais de autores estrangeiros que utilizam em suas abordagens o referencial da desagrarização.

Nessa perspectiva, na Figura 2 apresenta-se a diferenciação dos casos estudados, separandoos em dois grupos: os que aumentaram e os que diminuíram o valor do IAF entre os anos pesquisados. Destaca-se o valor do IAF de cada família em 2002 e 2017, separando-se as famílias em que ocorreu processo de agrarização (aumento do valor do IAF), daquelas em que ocorreu processo de desagrarização (diminuição do valor do IAF). Pode-se observar que a intensidade da variação no valor do IAF das famílias em desagrarização é maior do que nas famílias em agrarização. Entre as famílias em que ocorre desagrarização, o IAF passou de 0,77 para 0,43 (redução de 43,96\%), enquanto naquelas em que ocorre agrarização o IAF passou de 0,75 para 0,87 (elevação de 15,24\%). Ou seja, o processo de desagrarização, além de envolver maior número de famílias, é mais intenso que o processo de agrarização. 
Cabe registrar que Niederle (2007) e Conterato (2008), ao analisar as estratégias e estilos de agricultura desenvolvias pelos agricultores familiares de Salvador das Missões, já haviam apontado a perspectiva do processo de desagrarização das famílias. Essa perspectiva estava presente, especialmente, entre as famílias que adotavam estratégias baseadas na educação e migração, na diversificação das fontes de renda e na pluriatividade, ou que desenvolviam estilos de agricultura descapitalizados, voltados ao autoconsumo e dependentes de transferências sociais.

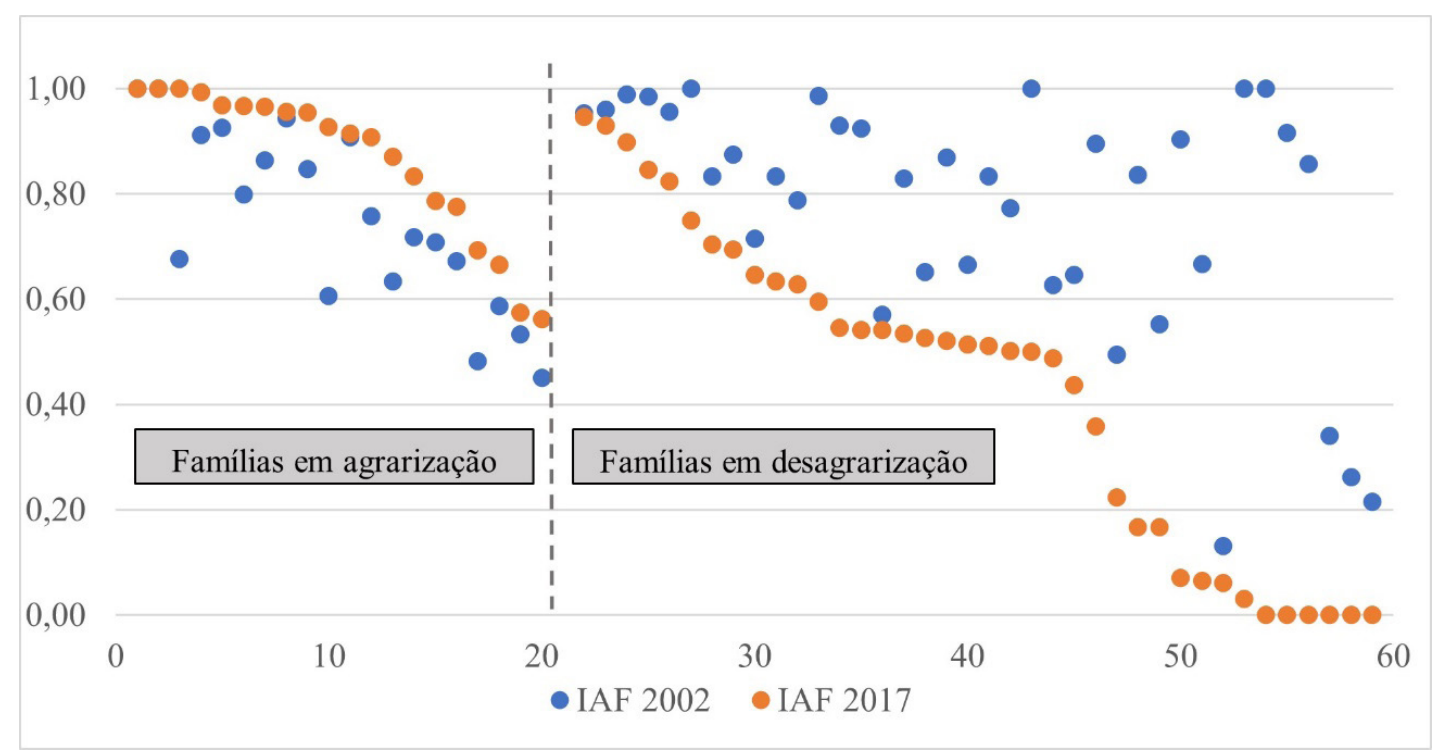

Figura 2 - IAF das famílias em processo de agrarização e desagrarização, Salvador das Missões - 2002 e 2017. Fonte: Pesquisa AFDLP (Grupo de Estudos e Pesquisas em Agricultura Familiar e Desenvolvimento Rural, 2004) e pesquisa de campo 2018.

De forma desagregada, os valores que compõem o IAF das famílias que aumentaram e diminuíram seu nível de agrarização podem ser observados na Tabela 2. Nas famílias em agrarização, destaca-se o expressivo aumento do IAR, elevação moderada do IAT e manutenção do IAD com o mesmo valor. Ou seja, nesses casos, ocorre um aumento da alocação do trabalho familiar em atividades agrícolas e forte crescimento da participação da renda agrícola na renda total, com a manutenção dos domicílios em espaços rurais.

Tabela 2 - Valores do IAF geral e desagregado das famílias em agrarização e desagrarização, Salvador das Missões - 2002 e 2017.

\begin{tabular}{cccccc} 
& \multicolumn{2}{c}{ Famílias em agrarização } & & \multicolumn{2}{c}{ Famílias em desagrarização } \\
\cline { 2 - 3 } \cline { 5 - 6 } Índices & $\mathbf{2 0 0 2}$ & $\mathbf{2 0 1 7}$ & & $\mathbf{2 0 0 2}$ & $\mathbf{2 0 1 7}$ \\
IAR & 0,47 & 0,77 & & 0,63 & 0,21 \\
IAT & 0,91 & 0,95 & & 0,88 & 0,55 \\
IAD & 0,88 & 0,88 & & 0,80 & 0,54 \\
IAF & 0,75 & 0,87 & & 0,77 & 0,43 \\
\hline
\end{tabular}

Fonte: Pesquisa AFDLP (Grupo de Estudos e Pesquisas em Agricultura Familiar e Desenvolvimento Rural, 2004) e pesquisa de campo 2018.

Nas famílias em desagrarização, ocorre sensível redução nas três dimensões que compõem o IAF. Destaca-se a diminuição do IAR, que cai expressivamente, mas o IAT e o IAD também diminuem. No caso dessas famílias, a participação da renda agrícola na renda total passa a 
ser secundária, mas o trabalho agrícola, apesar da redução, ainda cumpre importante papel na dinâmica familiar. No caso dos domicílios, ocorre expressivo processo de urbanização, o que aponta, em termos gerais, para o distanciamento domiciliar dos espaços rurais e, considerando a redução no IAR e IAT, também a adoção de estratégias de reprodução social menos vinculadas à agricultura.

Cabe ainda registrar a trajetória de desagrarização mais intensa de um grupo de dez famílias que, no segundo ano pesquisado, apresentavam IAF inferior a 0,10. Nesses casos, a intensidade do processo de desagrarização aponta para um expressivo distanciamento dessas famílias das atividades agrícolas e dos espaços rurais, coincidindo com os resultados das análises de Alves \& Rocha (2010), Guanziroli et al. (2012) e Buainain et al. (2013), sobre o estreitamento das possibilidades de reprodução social de parte dos agricultores familiares.

Por fim, torna-se evidente nessa primeira seção de resultados que a agrarização e a desagrarização são fenômenos paralelos no tempo, entre os agricultores familiares de Salvador das Missões. Esses processos conduzem as famílias em direções opostas quanto à importância das atividades agrícolas nas dinâmicas familiares, diferenciando-as expressivamente, como se evidenciará na seção que segue.

\subsection{Diferenciação das famílias em processo de agrarização e de desagrarização}

Nesta seção, apresenta-se os resultados da pesquisa referentes à diferenciação das famílias. São consideradas características demográficas e das condições produtivas que, ao serem confrontadas, comparativamente, evidenciam expressivas diferenças entre as famílias que seguem trajetórias de agrarização e desagrarização.

As características demográficas, apresentadas na Tabela 3, mostram que nos dois grupos ocorre redução do número médio de integrantes e aumento da sua idade média, entre 2002 e 2017, o que aponta, no conjunto dos casos estudados, para a diminuição do tamanho médio e o envelhecimento das famílias. Conforme Maia (2014), essas mudanças acompanham a tendência nacional de esvaziamento dos espaços rurais, associada a fatores endógenos e exógenos, como a queda na taxa de fecundidade, a fragmentação das famílias, a modernização da agricultura, as desigualdades territoriais e as melhores oportunidades de emprego e renda nos centros urbanos (Anjos \& Caldas, 2005; Sakamoto et al., 2016; Maia \& Buainain, 2015).

Também é importante destacar, como se observa na Tabela 3, que a desagrarização ocorre em famílias menores e mais velhas. Por outro lado, as famílias em que ocorre elevação do nível de agrarização são maiores e mais jovens. Além disso, outra dimensão que diferencia sensivelmente as famílias refere-se à composição de gênero de seus membros. Enquanto as famílias em agrarização mantêm inalterada a participação levemente superior de homens, nas famílias em desagrarização ocorre forte crescimento na participação de mulheres, evidenciando a associação entre o processo de desagrarização com o envelhecimento, a redução de tamanho e a feminização das famílias.

Tabela 3 - Características demográficas das famílias em processo de agrarização e desagrarização, Salvador das Missões - 2002 e 2017.

\begin{tabular}{|c|c|c|c|c|}
\hline & \multicolumn{2}{|c|}{ Famílias em agrarização } & \multicolumn{2}{|c|}{ Famílias em desagrarizaçãc } \\
\hline & 2002 & 2017 & 2002 & 2017 \\
\hline Idade média (anos) & 35,34 & 50,15 & 41,91 & 56,27 \\
\hline Número médio de integrantes & 4,70 & 3,45 & 4,08 & 2,95 \\
\hline Participação relativa homens & $52,13 \%$ & $52,17 \%$ & $52,90 \%$ & $46,43 \%$ \\
\hline Participação relativa mulheres & $47,87 \%$ & $47,83 \%$ & $47,10 \%$ & $53,57 \%$ \\
\hline
\end{tabular}

Fonte: Pesquisa AFDLP (Grupo de Estudos e Pesquisas em Agricultura Familiar e Desenvolvimento Rural, 2004) e pesquisa de campo 2018. 
Como consequência direta da maior intensidade no envelhecimento e na redução do tamanho das famílias em desagrarização, ocorre sensível diminuição da capacidade de trabalho familiar desse grupo. Pode-se observar, na Tabela 4, que a disponibilidade de mão de obra das famílias em agrarização também diminui, mas de forma menos intensa, ocorrendo, em paralelo, queda no número de famílias e também na proporção do trabalho familiar que é alocado em atividades não-agrícolas. Já o grupo em desagrarização segue trajetória oposta, com aumento do número de famílias e da proporção do trabalho familiar que é alocado em atividades não agrícolas, demarcando outro aspecto em que ocorre sensível diferenciação entre os dois grupos considerados, pois as famílias em agrarização distanciam-se da pluriatividade, enquanto nas famílias em desagrarização essa última ganha maior relevância ao longo do tempo.

Tabela 4 - Disponibilidade e alocação do trabalho das famílias em processo de agrarização e desagrarização, Salvador das Missões - 2002 e 2017.

\begin{tabular}{|c|c|c|c|c|}
\hline & \multicolumn{2}{|c|}{ Famílias em agrarização } & \multicolumn{2}{|c|}{$\begin{array}{c}\text { Famílias em } \\
\text { desagrarização }\end{array}$} \\
\hline & 2002 & 2017 & 2002 & 2017 \\
\hline Disponibilidade familiar de trabalho & $\begin{array}{l}\text { 2,96 UTHs/ } \\
\text { família }\end{array}$ & $\begin{array}{l}2,80 \text { UTHs/ } \\
\text { família }\end{array}$ & $\begin{array}{l}\text { 2,97 UTHs/ } \\
\text { família }\end{array}$ & $\begin{array}{c}\text { 1,73 UTHs/ } \\
\text { família }\end{array}$ \\
\hline Famílias com atividades não agrícolas & $45 \%$ & $25 \%$ & $31,58 \%$ & $47,37 \%$ \\
\hline Trabalho familiar alocado em & $8,56 \%$ & $4,13 \%$ & $15,06 \%$ & $37,91 \%$ \\
\hline
\end{tabular}

Fonte: Pesquisa AFDLP (Grupo de Estudos e Pesquisas em Agricultura Familiar e Desenvolvimento Rural, 2004) e pesquisa de campo 2018.

O acesso à terra e a disponibilidade de capital também constituem importantes vetores no processo de diferenciação das famílias investigadas. As famílias em processo de agrarização aumentaram a área média utilizada (passou de 14,07 ha para 23,62 ha), através da compra e do arrendamento da terra de terceiros. Além deste incremento, elevaram sensivelmente o valor médio do capital disponível (passou de, aproximadamente, 49 mil reais para 191 mil reais), evidenciando uma estratégia de priorização das atividades agrícolas. Em perspectiva diversa, o grupo em processo de desagrarização reduziu o tamanho da área média utilizada (passou de 17,86 ha para 12,38 ha) e apresentou leve descapitalização no período, pois o capital médio familiar passou de, aproximadamente, 73 mil reais para 69 mil reais ${ }^{3}$.

A diferenciação das famílias em termos de especialização produtiva, de investimento em tecnologia, que se expressa no volume de capital mobilizado nas atividades agrícolas, crescente nas famílias em agrarização e decrescente nas famílias em desagrarização, resultou em forte processo de concentração do valor produzido. No primeiro ano da pesquisa, as famílias do grupo em agrarização respondiam por 30,56\% do Valor Bruto da Produção, que passa para $63,64 \%$, no segundo ano pesquisado. Esse resultado alinha-se às conclusões de Alves \& Rocha (2010) e de Buainain et al. (2013) sobre o processo de diferenciação e de concentração do valor da produção entre as famílias agricultoras. Todavia, diferente desses autores, em que a variável tecnologia tem centralidade explicativa, os resultados da pesquisa realizada evidenciam que o processo de concentração da produção, entre as famílias pesquisadas, também se associa à variável terra, pois a superfície agrícola utilizada foi crescente nas famílias em agrarização e decrescente nas famílias em desagrarização.

O conjunto das alterações apontadas, tanto na disponibilidade e alocação de trabalho familiar, na área utilizada e no capital mobilizado em atividades agrícolas, contribuiu para a

${ }^{3}$ Como descrito na metodologia, os valores monetários de 2002 foram atualizados para 2017. 
diferenciação das famílias em relação à composição relativa de suas rendas. Como pode-se observar na Figura 3, as famílias em processo de agrarização aumentaram expressivamente sua dependência relativa da renda agrícola, com forte redução da renda não-agrícola e diminuição dos recursos oriundos da previdência social, destacadamente de aposentadoria rural. Essa última modalidade de renda é responsável por não tornar essas famílias totalmente dependentes da agricultura, pois em 2017, as demais fontes são relativamente pouco importantes na composição da renda total.

Quanto às famílias em processo de desagrarização, ocorre forte queda na participação relativa da renda agrícola na renda total, mesmo que ela ainda responda por cerca de um terço dos rendimentos familiares, revelando que essas famílias, apesar do processo de desagrarização, mantiveram parte do viés agrícola em suas atividades. Destaca-se o aumento da importância relativa dos recursos oriundos da previdência rural e também de atividades não agrícolas, o que diferencia esse grupo das famílias em processo de agrarização, pois a desagrarização implica em diversificação das fontes de renda.

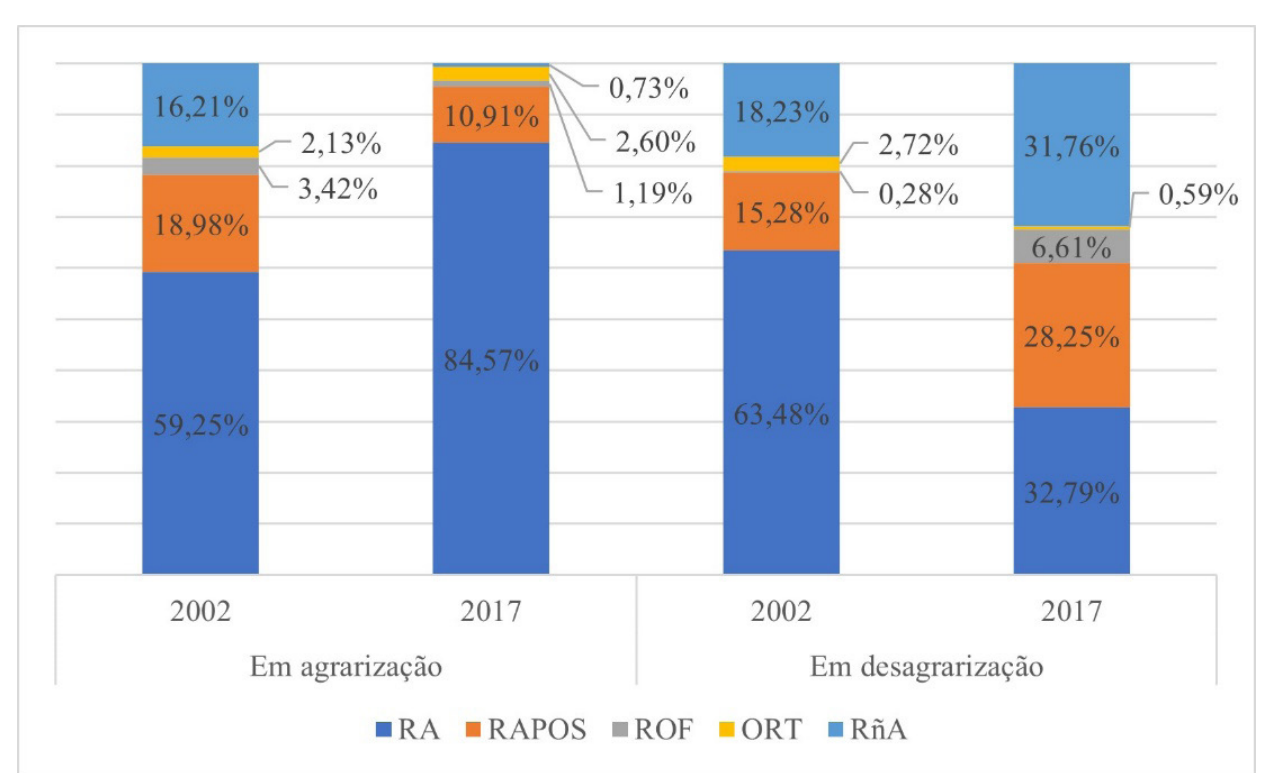

Figura 3 - Composição relativa da renda das famílias em agrarização e em desagrarização, Salvador das Missões - 2002 e 2017. Fonte: Pesquisa AFDLP (Grupo de Estudos e Pesquisas em Agricultura Familiar e Desenvolvimento Rural, 2004) e pesquisa de campo 2018.

Outro achado importante deste estudo, em termos de diferenciação das famílias, refere-se ao valor da renda per capita. Diferente das pesquisas que apontam para uma tendência de menor renda das famílias com maior dedicação às atividades agrícolas em relação àquelas que recorrem à diversificação das rendas, especialmente através da pluriatividade (Schneider et al., 2006; Anjos \& Caldas, 2007; Schneider, 2009; Sakamoto et al., 2016; Musatto \& Santos, 2016; Villwock \& Perondi, 2017; Villwock, 2018), desde a perspectiva de análise dos processos de agrarização e desagrarização das famílias, o que se aponta é o contrário.

Entre os anos pesquisados, as famílias em processo de agrarização tiveram crescimento de renda muito mais intenso que as famílias em desagrarização. Enquanto a renda per capita mensal do grupo em agrarização passou de 0,68 para 3,99 salários mínimos (SM4), no grupo

${ }^{4}$ Considerando o valor do salário mínimo vigente em setembro de 2017 e atualizando o valor do salário mínimo de 2002 para este mesmo mês, como descrito na metodologia. 
em desagrarização, essa dimensão passou de 1,28 para 2,34 SM. Portanto, mesmo que menos diversificada, a renda per capita mensal das famílias em agrarização tornou-se expressivamente superior àquela das famílias em desagrarização. Além de diferenciação das famílias quanto ao nível da renda familiar, os resultados do estudo alinham-se às conclusões do trabalho de Guanziroli et al. (2012), que aponta para o processo de concentração de valores maiores em um grupo numericamente menor de famílias.

Com a incorporação do enfoque territorial nas narrativas de desenvolvimento rural, no final do século XX (Favareto \& Berdegue, 2018), destaca-se que a dimensão rural e a territorial dialogam fortemente entre si e que a noção de território não pode prescindir da consideração das dinâmicas dos espaços rurais (Leite, 2020). Aqui reside relevante campo de análise a ser futuramente explorado, que são as interfaces entre os processos de agrarização e desagrarização da agricultura familiar, identificados pelo presente estudo e as diferentes implicações que eles geram para a ruralidade e o futuro das regiões rurais.

Além disso, cabe registrar algumas hipóteses atualmente cogitadas para a continuidade do estudo e a busca dos fatores causais do processo de diferenciação ora identificado. Observouse distintas tendências entre as famílias em agrarização e desagrarização quanto ao acesso as políticas públicas, marcadamente o acesso ao crédito e à assistência técnica, sendo ela crescente entre as primeiras e decrescente entre as segundas. A literatura tem destacado a relevância dessas variáveis como elementos explicativos da diferenciação dos agricultores (Gazolla \& Schneider, 2013; Aquino, Gazolla \& Schneider, 2018; Guanziroli \& Vinchon, 2019; Rocha Júnior et al., 2020), o que fortalece o acesso as políticas públicas como uma das hipóteses explicativas a ser verificada. Todavia, de modo diverso ao sugerido em outros trabalhos (Grisa \& Schneider, 2015; Becker \& Anjos, 2015; Swensson, 2019), o acesso aos mercados públicos institucionais (Schneider, 2016) parece não ter sido uma variável tão relevante nas trajetórias identificadas, dado o reduzido número de famílias que acessaram essa política, o que sublinha a necessidade de considerar-se as diferentes implicações das distintas políticas públicas nas trajetórias de agrarização e desagrarização.

Por fim, as análises sobre as dinâmicas dos espaços rurais contemporâneas, refletidas na literatura sobre desenvolvimento rural e suas transformações, tornam necessária a consideração, como hipóteses explicativas, analisar a relação dos processos de agrarização e desagrarização com outras variáveis. Pode-se apontar, as implicações das variações demográficas, sobretudo os processo de envelhecimento e redução do tamanho das famílias, bem como o êxodo rural contemporâneo (Maia, 2014; Thies, 2021), o acesso à terra (Fernandes, 2018), a disponibilidade de capital e tecnologia, além da questão da produtividade (Buainain et al., 2013; Hein \& Silva, 2019).

Testar a capacidade explicativa dessas variáveis é parte da atual agenda para o avanço do estudo sobre os processos de agrarização e desagrarização da agricultura familiar. Além disso, deve-se considerar esse fenômeno no âmbito das mudanças em curso no contexto rural contemporâneo, onde pode-se destacar importantes processos que afetam a totalidade dos agricultores como, por exemplo, o boom das commodities no setor agropecuário brasileiro (Silveira, 2017) e a forte elevação dos preços das terras, especialmente aquelas mais aptas ao cultivo de soja (Bacha, Stege, \& Harbs, 2016; Fritz et al., 2018), como é o caso de Salvador das Missões.

\section{CONSIDERAÇÕES FINAIS}

No presente artigo analisou-se a dinâmica de diferenciação social na agricultura, tendo como objetivo identificar a ocorrência de processos de agrarização e desagrarização entre agricultores familiares. Com base nas formulações pioneiras de Bryceson (1996), foi utilizado o IAF como 
indicador desses processos em nível microanalítico, o que permitiu distinguir as trajetórias e a diferenciação das famílias ao longo do tempo. Destaca-se daí relevante contribuição do trabalho, ao revelar as características do processo de agrarização de parte das famílias pesquisadas.

A análise realizada permitiu demonstrar que o processo de desagrarização envolveu maior número de famílias e mostrou-se mais intenso que a agrarização. Apesar de apontar para direções opostas, evidenciou-se que ambos são fenômenos paralelos ao longo do tempo, quando a unidade de análise são as famílias agricultoras. Aí reside outra contribuição para os estudos agrários pois, diferente do que usualmente é enfatizado nas formulações sobre desagrarização, sobretudo aquelas que tomam como unidade de análise determinado recorte geográfico, o presente trabalho destaca que o distanciamento das atividades agrícolas não pode ser generalizado como parte de um processo homogêneo, que ocorre em sentido linear, variando do agrarizado em direção ao desagrarizado. Como demonstrado, desde o enfoque das trajetórias familiares, ganha relevo, para parte expressiva do grupo estudado, o processo de crescente agrarização.

Assim, em termos teóricos, sugere-se uma inflexão na abordagem da desagrarização, não devendo ser tomada como o único ângulo de análise das dinâmicas de desenvolvimento rural, pois tal foco pode velar parte relevante das dinâmicas contemporâneas. Em termos analíticos, a desagrarização deve, necessariamente, ser considerada de forma articulada com sua contraface, ou seja, a agrarização. Para tal, considera-se que o uso do índice de agrarização familiar (IAF) cumpre de forma satisfatória o papel de captar, mensurar e contribuir a interpretar os processos de agrarização e de desagrarização, permitindo, como evidenciado, identificar substantiva diferenciação dos agricultores familiares ao longo do tempo.

O avanço dos estudos, sob a ótica da agrarização e da desagrarização das famílias agricultoras, passa por uma agenda que inclua a repetição deste estudo em outros espaços, para a comparação de resultados e o aprimoramento da metodologia proposta. Além desta perspectiva, convém, com a identificação da existência dos processos de agrarização e de desagrarização das famílias, analisar futuramente as causas destas diferentes trajetórias, colocando-as em conexão com as dinâmicas e variáveis meso e macroanalíticas, bem como suas interfaces com a ruralidade e o desenvolvimento dos territórios. Por fim, espera-se o aprimoramento da abordagem aqui inaugurada, através do debate com todos os interessados nas dinâmicas de desenvolvimento rural.

\section{REFERÊNCIAS}

Alatrista, S. L. (2019). Desagrarización del empleo femenino rural y tiempos de trabajo en el Perú. Investigaciones Sociales, 22(42), 223-243.

Alves, E., \& Rocha, D. P. (2010). Ganhar tempo é possível. In J. Gasques, J. E. R. Vieira Filho \& Z. Navarro (Orgs.), A agricultura brasileira: desempenho recente, desafios e perspectivas (pp. 275-291). Brasília: IPEA/MAPA.

Anjos, F. S., \& Caldas, N. V. (2005). O futuro ameaçado: o mundo rural face aos desafios da masculinização, do envelhecimento e da desagrarização. Ensaios FEE, 26(1), 661-694.

Anjos, F. S., \& Caldas, N. V. (2007). Sob o efeito da desagrarização: agricultura familiar e pluriatividade no Rio Grande do Sul. Estudos Sociedade e Agricultura, 15(2), 310-339.

Anjos, F. S., Caldas, N. V., \& Pollnow, G. E. (2014). Menos mulheres, menos jovens, mais incertezas: a transição demográfica no Brasil rural meridional. Revista Extensão Rural, 21(2), 94-116. 
Aquino, J., Gazolla, M., \& Schneider, S. (2018). Dualismo no campo e desigualdades internas na Agricultura Familiar Brasileira. Revista de Economia e Sociologia Rural, 56(1), 123-142.

Bacha, C. J. C., Stege, A. L., \& Harbs, R. (2016). Ciclos de preços de terras agrícolas no Brasil. Revista de Política Agrícola, 4, 18-37.

Banchirigah, S. M., \& Hilson, G. (2010). De-agrarianization, re-agrarianization and local economic development: re-orientating livelihoods in African artisanal mining communities. Policy Sciences, 43, 157-180.

Becker, C., \& Anjos, F. S. (2015). São os mercados institucionais da agricultura familiar um instrumento para o desenvolvimento rural? Estudo de caso em municípios do sul do Brasil. Revista de la Facultad de Agronomía, 114(1), 143-152.

Belik, W. (2015). O financiamento da agropecuária brasileira no período recente: texto para discussão (62 p.). Brasília: IPEA.

Black, C. (2015). Preços de commodities, termos de troca e crescimento econômico brasileiro nos anos 2000. Indic. Econ. FEE, 42(3), 27-44.

Boscardin, M., \& Spanevello, R. M. (2019). A importância da aposentadoria rural para agricultores familiares sem sucessores no norte do Rio Grande do Sul: o caso do município de Frederico Westphalen. Estudo \& Debate, 26(2), 35-51.

Bowen, S. (2011). The importance of place: re-territorialising embeddedness. Sociologia Ruralis, 51(4), 325-348.

Bryceson, D. F. (1996). Deagrarianization and rural employment in sub-Saharan Africa: a sectoral perspective. World Development, 24(1), 97-111.

Bryceson, D. F. (2018). Deagrarianization and depeasantization in Africa: tracing sectoral transformation and rural income diversification. In T. Binns, K. Lynch \& E. Nel (Orgs.), Handbook of African Development. (pp. 368-377). Abingdon: Routledge.

Bryceson, D. F. (2019). Gender and generational patterns of African deagrarianization: evolving labor and land allocation in smallholder peasant household farming, 1980-2015. World Development, 113, 60-72.

Buainain, A. M., Alves, E., Silveira, J. M., \& Navarro, Z. (2013). Sete teses sobre o mundo rural brasileiro. Revista de Política Agrícola, Brasilia, 22(2), 105-121.

Camarano, A. A., \& Abramovay, R. (1999). Êxodo rural, envelhecimento e masculinização no Brasil: panorama dos últimos 50 anos. Rio de Janeiro: IPEA.

Collantes, J. C. A. (2002). Desagrarización del caseiro y abandono forestal. Estudios Vascos, 16, 11-30.

Conterato, M. A. (2004). A mercantilização da agricultura familiar no Alto Uruguai/RS: um estudo de caso no município de Três Palmeiras (Dissertação de mestrado). Faculdade de Ciências Econômicas, Universidade Federal do Rio Grande do Sul, Porto Alegre.

Conterato, M. A. (2008). Dinâmicas regionais do desenvolvimento rural e estilos de agricultura: uma análise a partir do Rio Grande do Sul (Tese de doutorado). Faculdade de Ciências Econômicas, Universidade Federal do Rio Grande do Sul, Porto Alegre.

Diniz, J. D. A., \& Cerdan, C. (2017). Produtos da sociobiodiversidade e cadeias curtas: aproximação socioespacial para uma valorização cultural e econômica. In M. Gazolla \& S. Schneider (Orgs.), Cadeias curtas e redes agroalimentares alternativas. Negócios e mercados da agricultura familiar (pp. 259-280). Porto Alegre: UFRGS. 
Escalante, R., Catalán, H., Galindo, L. M. L., \& Reyes, O. (2007). Desagrarización en México: tendencias actuales y retos hacia el futuro. Cuadernos de Desarrollo Rural, 4, 87-116.

Escher, F., Schneider, S., Scarton, L. M., \& Conterato, M. A. (2014). Caracterização da pluriatividade e dos plurirrendimentos da Agricultura Brasileira a partir do Censo Agropecuário. Revista de Economia e Sociologia Rural, 52(04), 643-668.

Favareto, A., \& Berdegue, J. (2018). Mudanças globais e locais - implicações para o futuro do enfoque territorial do desenvolvimento rural em América Latina. In M. E. V. Perafan, C. Grisa, I. Tartaruga \& C. A. Ramirez-Miranda (Orgs.), Gestão e dinâmicas em desenvo/vimento territorial (pp. 29-54). Curitiba: Editora DRV.

Fernandes, B. M. (2018). Regimes alimentares, impérios alimentares, soberanias alimentares e movimentos alimentares. Revista Latinoamericana de Estudios Rurales, 04, 188-209.

Fra, M. M. P. (2016). O espaço rural, recurso ou problema? O caso das áreas rurais galegas. Revista de Extensão e Estudos Rurais, 5(1), 21-32.

Fritz, E. R., Oliveira, S. V., Andreatta, T., \& Lago, A. (2018). A análise do mercado de terras no estado do Rio Grande do Sul. In Anais do $3^{\circ}$ Seminário de Jovens Pesquisadores em Economia e Desenvolvimento. Santa Maria: UFSM. Recuperado em 23 de novembro de 2019, de http://coral.ufsm.br/seminarioeconomia/images/anais_2015/Anlise-do-Mercadode-Terras-do-Estado-do-Rio-Grande-do-Sul.pdf

Garcés, C. R., Yissi, M. J. F., \& Muñoz, J. A. S. (2017). Demographic and labor market transformations in rural areas of Chile. Acta Agronomica, 66(2), 200-206.

Gazolla, M., \& Schneider, S. (2013). Qual "fortalecimento" da agricultura familiar? uma análise do Pronaf crédito de custeio e investimento no Rio Grande do Sul. Revista de Economia e Sociologia Rural, 51(1), 46-70.

Grammont, H. C. (2009). La desagrarización del campo mexicano. Convergencia, 50, 13-55.

Grando, M. A. (2012). Um retrato da agricultura familiar gaúcha. Indic. Econ. FEE, 39(4), 159-176.

Grisa, C., \& Schneider, S. (2015). Três gerações de políticas públicas para a agricultura familiar e formas de interação entre sociedade e Estado no Brasil. In C. Grisa \& S. Schneider (Orgs.), Políticas públicas de desenvolvimento rural no Brasil (pp. 19-50). Porto Alegre: Editora da UFRGS.

Grupo de Estudos e Pesquisas em Agricultura Familiar e Desenvolvimento Rural - GEPAD. (2004). Agricultura familiar, desenvolvimento local e pluriatividade no Rio Grande do Sul: a emergência de uma nova ruralidade (AFDLP). Porto Alegre: GEPAD.

Guanziroli, C. H., \& Vinchon, K. (2019). Agricultura familiar nas regiões serrana, norte e noroeste fluminense: determinantes do processo de geração de renda. Revista de Economia e Sociologia Rural, 57(3), 353-367.

Guanziroli, C. H., Buainain, A. M., \& Sabbato, A. (2012). Dez anos de evolução da agricultura familiar no Brasil: (1996 e 2006). Revista de Economia e Sociologia Rural, 50(2), 351-370.

Guedes, A. C., Cazella, A. A., \& Capelesso, A. J. (2018). O arrendamento de terras no Brasil: subsídios para políticas públicas. Revista Grifos, 44, 104-125.

Gutiérrez, F. C. (2007). La desagrarización de la sociedad rural española, 1950-1991. Historia Agraria, 42, 251-276.

Gutiérrez, F. C., \& Martín, R. D. (2006). La demografía importa: convergencia y cambio estructural por defecto en las regiones y provincias españolas, 1959-1999. Revista Latinoamericana de Economia, 37(146), 147-168. 
Hein, A. F., \& Silva, N. L. S. (2019). A insustentabilidade na agricultura familiar e o êxodo rural contemporâneo. Estudos Sociedade e Agricultura, 27(2), 394-417.

Hernández, D. G., \& Sánchez, I. V. (2010). Desagrarización cultural, agricultura urbana y resistencias para la sustentabilidade. PH CUADERNOS, 51-71.

Instituto Brasileiro de Geografia e Estatística - IBGE. (2000). Censo Demográfico de 2000. Recuperado em 14 de dezembro de 2019, de https://www.fee.rs.gov.br/perfil-socioeconomico/ estado/divisao-geopolitica-do-rs/.

Instituto Brasileiro de Geografia e Estatística - IBGE. (2010). Censo Demográfico de 2010. Recuperado em 14 de dezembro de 2019, de https://www.fee.rs.gov.br/perfil-socioeconomico/ estado/divisao-geopolitica-do-rs/.

Instituto Brasileiro de Geografia e Estatística - IBGE. (2017). Censo Agropecuário 2017. Recuperado em 15 de outubro de 2019, de https://sidra.ibge.gov.br/pesquisa/censo-agropecuario/ censo-agropecuario-2017.

Kageyama, A. A., Bergamasco, S. M. P. P., \& Oliveira, J. T. A. (2013). Uma tipologia dos estabelecimentos agropecuários do Brasil a partir do Censo de 2006. Revista de Economia e Sociologia Rural, 51(1), 105-122.

Leite, S. P. (2020). Ruralidades, enfoque territorial e políticas públicas diferenciadas para o desenvolvimento rural brasileiro: uma agenda perdida? Estudos Sociedade e Agricultura, 28(1), 227-254.

Lima, A. J. P., Basso, N., Neumann, P. S., Santos, A. C., \& Müller, A. G. (1995). Administração da unidade de produção familiar: modalidades de trabalho com agricultores. Ijuí: Editora UNIJUÍ.

Long, N. (2007). Sociología del desarrollo: una perspectiva centrada en el actor. México: Ciesas.

Long, N., \& Ploeg, J. D. V. D. (2011). Heterogeneidade, ator e estrutura: para a reconstituição do conceito de estrutura. In S. Schneider \& M. Gazolla (Orgs.), Os atores do desenvo/vimento rural: perspectivas teóricas e práticas (pp. 21-48). Porto Alegre: Editora da UFRGS.

Lui, G. H. (2013). Transição de modos de vida rurais na Amazônia brasileira: uma perspectiva longitudinal sobre diversificação da renda, atividades agrícolas e uso da terra entre pequenos produtores (Tese de doutorado). Centro de Energia Nuclear na Agricultura, Universidade de São Paulo, Piracicaba.

Maia, A. G. (2014). O esvaziamento demográfico rural. In A. M. Buainain, E. Alves, J. M. Silveira \& Z. Navarro (Orgs.), O mundo rural no Brasil do século 21: a formação de um novo padrão agrário e agrícola (pp. 1081 - 1099). Brasília: EMBRAPA.

Maia, A. G., \& Buainain, A. M. (2015). O novo mapa da população rural brasileira. Confins, (25), $1-26$.

Manona, C. (1999). De-agrarianisation and the urbanisation of a rural economy: agrarian patterns in Melani village in the Eastern Cape: working paper (50 p.). Leiden: Afrika Studie Centrum.

Marconi, M. A., \& Lakatos, E. M. (2010). Metodologia científica. São Paulo: Editora ATLAS.

Musatto, R. M., \& Santos, R. A. (2016). Pluriatividade na agricultura familiar na comunidade Palmeirinha no município de Itapejara d'Oeste - PR. Campo-Território: Revista de Geografia Agrária, 11(24), 124-155.

Niederle, P. A. (2007). Mercantilização, estilos de agricultura e estratégias reprodutivas dos agricultores familiares de Salvador das Missões, RS. (Dissertação de mestrado). Faculdade de Ciências Econômicas, Universidade Federal do Rio Grande do Sul, Porto Alegre. 
Niederle, P. A. (2013). Indicações geográficas: Qualidade e origem nos mercados alimentares. Porto Alegre: Editora da UFRGS.

Niederle, P. A., Fialho, M. A. V., Conterato, M. A. (2015). A pesquisa sobre Agricultura Familiar no Brasil - aprendizagens, esquecimentos e novidades. RESR, 52(1), 9-24.

Niederle, P. A., \& Wesz Júnior, V. J. (2018). As novas ordens alimentares. Porto Alegre: Editora da UFRGS.

Picolotto, E. L. (2011). As mãos que alimentam a nação: agricultura familiar, sindicalismo e política (Tese de doutorado). Instituto de Ciências Humanas e Sociais, Universidade Federal Rural do Rio de Janeiro, Rio de Janeiro.

Ploeg, J. D. V. D. (2008). Camponeses e impérios alimentares: lutas por autonomia e sustentabilidade na era da globalização. Porto Alegre: Editora da UFRGS.

Ploeg, J. D. V. D. (2017). Differentiation: old controversies, new insights. The Journal of Peasant Studies, 45(3), 489-524.

Pontili, R. M., Staduto, J. A. R., \& Henrique, J. S. (2015). Uma discussão do desenvolvimento rural sob o enfoque da participação da população trabalhadora do meio rural em atividades agrícolas e não agrícolas. Ciências Sociais em Perspectiva, 14(26), 196-215.

Preiss, P. V., \& Schneider, S. (2020). Sistemas alimentares no século XXI: debates contemporâneos. Porto Alegre: Editora da UFRGS.

Quintanal, H. S., \& Fuente, Í. G. (2013). Nueva ruralidad. Procesos sociolaborales y desagrarización de uma sociedad local en México (1980-2010). Gazeta de Antropología, 29, 1-14.

Rehder, A., Déhu, C. B. M., Rogna, M., Hasan, M. K., Wæver, S. K., \& Gebremedhin, T. T. (2011). Intensification of agriculture and deagrarianization: final report (96 p.). Chiang Mai: Interdisciplinary Land Use and Natural Resources Management.

Rigg, J., \& Nattapoolwat, S. (2001). Embracing the global in Thailand: activism and pragmatismo in na era of deagrarianization. World Development, 29(6), 945-960.

Rocha Júnior, A. B., Silva, R. O., Peterle Neto, W., \& Rodrigues, C. T. (2020). Efeito da utilização de assistência técnica sobre a renda de produtores familiares do Brasil no ano de 2014. Revista de Economia e Sociologia Rural, 58(2), 1-16.

Sabourin, E., Samper, M., \& Sotomayor, O. (2015). Políticas públicas y agriculturas familiares en América Latina y el Caribe: nuevas perspectivas. San José: IICA.

Sakamoto, C. S., Nascimento, C. A., \& Maia, A. G. (2016). As famílias pluriativas e não agrícolas no rural brasileiro: condicionantes e diferenciais de renda. Revista de Economia e Sociologia Rural, 54(3), 561-582.

Schneider, S. (2003). Teoria social, agricultura familiar e pluriatividade. Revista Brasileira de Ciências Sociais, 18(51), 99-121.

Schneider, S. (2009). Agricultura familiar e desenvolvimento rural endógeno: elementos teóricos e um estudo de caso. In J. M. Froehlich \& V. Diesel (Orgs.), Desenvolvimento Rural: tendências e debates contemporâneos (pp. 19-67). ljuí: Unijuí.

Schneider, S. (2016). Mercados e agricultura familiar. In F. C. Marques, M. A. Conterato \& S. Schneider (Orgs.), Construção de mercados e agricultura familiar. desafios para o desenvolvimento rural (pp. 93-140). Porto Alegre: Editora da UFRGS.

Schneider, S., Conterato, M. A., Koppe, L. R., \& Silva, C. C. (2006). A pluriatividade e as condições de vida dos agricultores familiares do Rio Grande do Sul. In S. Schneider (Org.), A diversidade da agricultura familiar (pp. 139-166). Porto Alegre: Editora da UFRGS. 
Silva, J. (2001). Velhos e novos mitos do rural brasileiro. Estudos Avançados, 15(43), 37-50.

Silveira, F. G. (2017). O trabalho agrícola no boom do agronegócio e na expansão das políticas públicas para a pequena agricultura. Mercado de Trabalho, 63, 28-38.

Souza, R. P., \& Buainain, A. M. (2013). A competitividade da produção de leite da agricultura familiar: os limites da exclusão. Estudos Sociedade e Agricultura, 21(2), 308-331.

Spanevello, R., Matte, A., Andreatta, T., \& Lago, A. (2017). A problemática do envelhecimento no meio rural sob a ótica dos agricultores familiares sem sucessores. Desenvolvimento Em Questão, 15(40), 348-372.

Swensson, L. F. J. (2019). Programas institucionais de aquisição de alimentos e organizações de produtores: catalisadores para a transformação de sistemas de abastecimento de alimentos de pequenos produtores. Redes, 24(1), 30-44.

Thies, V. F. (2020). Desagrarização e concentração produtiva: análise longitudinal das trajetórias da agricultura familiar nas Missões do RS (Tese de doutorado). Faculdade de Ciências Econômicas, Universidade Federal do Rio Grande do Sul, Porto Alegre.

Thies, V. F. (2021). Transformações demográficas e nas estratégias de trabalho: uma abordagem longitudinal da agricultura familiar em Salvador das Missões - Rio Grande do Sul. Redes, 26, 1-19.

Vázquez, F. P., \& Mazariegos, J. V. (1991). La implicación de la mujer en la agricultura familiar: apuntes sobre el proceso de desagrarización en España. Politics \& Society, 9, 15-28.

Villwock, A. P. S. (2018). Meios de via e renda: uma pesquisa em painel de agricultores familiares do sudoeste do Paraná (Tese de doutorado). Programa de Pós-Graduação em Extensão Rural, Universidade Federal de Santa Maria, Santa Maria.

Villwock, A. P. S., \& Perondi, M. A. (2017). Análise dos indicadores socioeconômicos de diferentes estratos de renda da agricultura familiar de Itapejara D'Oeste-PR. Revista Mundi Meio Ambiente e Agrárias, 2(2), 1-23. 